\title{
La inversión extranjera directa: el caso de los capitales brasileños en Chile
}

\author{
Foreign direct investment: the case of \\ Brazilian capitals in Chile
}

\author{
Dorotea López G. \\ Felipe Muñoz N.*
}

\begin{abstract}
Resumen
El crecimiento de los flujos de inversión extranjera directa entre los países de América Latina es un fenómeno reciente. En este contexto, Brasil se ha convertido en importante polo de atracción de inversiones para Chile, a pesar de que los capitales provenientes de ese país representan un bajo porcentaje del total recibido. El presente artículo examina las inversiones brasileñas en Chile, con especial referencia a las percepciones de los principales actores de los sectores público, académico y privado involucrados en el proceso de inversión, tanto chilenos como brasileños. Si bien en Chile hay consenso en la importancia de atraer capitales brasileños y en que el país continúa siendo un destino atractivo para los inversionistas, el reducido tamaño de su mercado, los recientes conflictos laborales y los altos costos así como el hecho de que el país no esté adecuadamente preparado para convertirse en una plataforma
\end{abstract}

Profesora Asistente, Instituto de Estudios Internacionales, Universidad de Chile. < dolopez@ uchile.cl>.

** Profesor Ayudante, Instituto de Estudios Internacionales, Universidad de Chile. <fmunozn@ uchile.cl>.

Recibido el 3 de junio de 2008; aceptado el 27 de junio de 2008.

Este artículo forma parte del proyecto de investigación «Inversiones brasileñas en Sudamérica: la Perspectiva de los países andinos» encargado por la Fundação Centro de Estudos do Comércio Exterior (FUNCEX), y el Centro de Estudos de Integração e Desenvolvimiento (CINDES), de Brasil, y financiado por la Agencia Suiza de Cooperación (COSUDE). Agradecemos los valiosos comentarios del Profesor Francisco Prieto S. a versiones preliminares de este artículo. Asimismo a Sandra Ríos, Fernando Ribeiro y los participantes del seminario sobre inversiones brasileñas en América Latina realizado en Río de Janeiro en abril de 2008. 
de exportaciones plantean la necesidad de reformular el escenario para hacerlo más atractivo para los inversionistas. Finalmente, se proponen temas para una posible agenda de carácter bilateral en esta materia.

PAlabras Clave: Inversión extranjera directa, flujos de capitales brasileños, inversión en Chile, plataforma de exportaciones, agenda bilateral.

\section{Abstract}

The increasing investment flows within Latin American countries is a recent experience. In this context, Brazil has become a relevant investment pole for Chile, although capitals from that country represent a low percentage of overall investment. This paper examines Brazilian investments in Chile, with special reference to perceptions of public, academic and governmental actors involved in developing investment. There is consensus on benefits of Brazilian investment for Chile and that the country continues to be attractive for foreign capitals. However, the small size of its market, labor conflicts and costs, and the fact that it is inadequately prepared to act as a hub for the rest of the world, urgently requires reformulating the Chilean scenario for investors. Finally, some topics for a bilateral agenda in this field are proposed.

KeY words: Foreign direct investment, Brazilian capital flows, investment in Chile, exports hub, bilateral agenda. 


\section{INTRODUCCIÓN}

Dentro de la activa política de inserción internacional aplicada por Chile, la inversión extranjera directa (IED) se ha convertido en uno de los ejes fundamentales de la economía, al punto que en los últimos veinticinco años dicha inversión ha jugado un importante rol en su sostenido crecimiento económico. De 1990 a la fecha, el país ha recibido alrededor de 91.000 millones de dólares de IED y en 2007 el monto autorizado tan solo por el Comité de Inversión Extranjera representó un crecimiento de $24 \%$ respecto del año anterior.

La región ha ocupado un lugar importante en la definición de esta política de inserción económica, si bien entre los países de América Latina el aumento en la tasa de inversión es un proceso muy reciente. Este fenómeno naciente se ha acompañado de un aumento del número de empresas transnacionales de la región, las denominadas «translatinas», que representan un motor de crecimiento y podrían desempeñar un papel importante en los flujos de IED intrarregional. Estas empresas provienen principalmente de Argentina, Brasil, Chile y México (CEPAL, 2005).

Asimismo, las políticas de atracción de inversiones aún son incipientes, en particular en lo que se refiere a la incorporación de la región como un potencial inversionista. Históricamente, Chile ha orientado sus esfuerzos de promoción como destino atractivo de capitales en especial hacia Estados Unidos y Europa. Sin embargo, América Latina, en particular Brasil, ha adquirido creciente interés para nuestro país, si bien ello no parece reflejarse en una política de carácter discriminatorio, como resultado de la aplicación del principio de neutralidad, pero sí en estrategias de orientación más definidas.

Este es el contexto en que se enmarca la relación de ambos países. Si bien dentro de Sudamérica Chile es importante receptor de IED, particularmente si se si considera el tamaño de su economía y Brasil el segundo país de destino de las inversiones directas de capitales chilenos en el mundo y concentra un $17 \%$ del total, la inversión brasileña directa (IBD) en Chile representa solamente un $0.51 \%$ del total de IED. ${ }^{1}$ De acuerdo con datos del último censo de las inversiones en el exterior realizado por el Banco Central de Brasil, en 2005 el stock de inversión brasileña en Chile era de 242 millones de dólares, lo que representa un $0.3 \%$ del total de la inversión de Brasil en el exterior. Asimismo, de acuerdo con informaciones del Banco Central de Brasil, los flujos de inversión ascendieron a 41 millones de dólares, un $0.17 \%$ del total, en 2006

1 Este dato representa la inversión brasileña a Chile a través del DL 600, desde 1974 a la fecha. 
y a 689 millones, un $6.3 \%$ del total, en $2007^{2}$.

Pese a la falta de datos estadísticos adecuados sobre el registro de la inversión, los capitales brasileños en Chile siguen constituyendo un porcentaje menor. Asimismo, a pesar de los riesgos externos e internos que han complicado el manejo macroeconómico, tales como la apreciación del peso, los recientes conflictos laborales, el precio de los commoditties, etc., Chile continúa siendo un destino atractivo para los inversionistas, con excelentes clasificaciones internacionales, tanto en lo que refiere a ambiente de negocios, como a muchos otros factores determinantes para la inversión. Además, estos riesgos no deben considerarse un problema, especialmente en el contexto regional en que las empresas están acostumbradas a mayores complejidades.

En vista de lo anterior, surge la necesidad de responder a ciertas interrogantes: ¿Qué determina el nivel de la inversión extranjera directa de Brasil en Chile?, ¿Es su volumen tan solo un problema de tamaño del mercado?, ¿Cuáles son las expectativas chilenas en lo que se refiere a las inversiones brasileras?, ¿Cuál es la percepción de las empresas brasileras que tienen inversiones directas en Chile? Además, hay que identificar y analizar temas relacionados con la inversión que son de interés tanto para Brasil como para Chile.

$<$ www.bcb.gov.br visitada el 15 de enero de $08>$.
En la primera sección se analiza la evolución de la IED, con especial referencia a Brasil. Posteriormente, se dan a conocer los resultados de las entrevistas realizadas por los autores a actores relevantes relacionados con la inversión brasileña directa entre los meses de diciembre de 2007 y abril de 2008. Las entrevistas se centraron en las percepciones de los diferentes sectores relacionados con la IBD (gobierno, sector privado y sociedad civil) respecto de los capitales brasileños, así como aquellas de los empresarios brasileños sobre Chile como destino de inversiones. Finalmente, se sugiere una agenda bilateral que tenga por objeto incrementar los flujos de capital entre ambos países.

\section{LA INVERSIÓN BRASILEÑA DIRECTA EN CHILE}

«En 1974, las nuevas autoridades chilenas decidieron dar un vuelco en la estrategia de desarrollo económico. Abandonaron la que había prevalecido desde la Gran Depresión, basada en una combinación de industrialización vía sustitución de importaciones, visión crítica del mercado e intervención creciente del gobierno en todas las facetas económicas nacionales, particularmente en las actividades productivas»(Hachette, 1998). El nuevo paradigma por el cual se guiaría el desarrollo nacional estaría basado en una economía de mercado, abierta a la participación de los privados y donde el Estado se limitaría a un 
Dorotea López y Felipe MuÑoz • La inversión extranjera directa...

rol regulador. Complementariamente y conscientes de la escasez de capitales nacionales, se elaboró una política para atraer IED, en la que destaca la promulgación del D.L. 600.

A pocos meses de promulgado este Decreto Ley, la IED comenzó a mostrar un dinamismo sin precedentes en la economía chilena. Si bien gran parte de las inversiones ingresadas al país se amparaba en este decreto, «la gran afluencia de inversión... en el último decenio no es producto exclusivamente de la mencionada legislación, sino también de una serie de reformas llevadas a cabo en la economía y en particular del sector externo durante el mismo período. Estas reformas han liberalizado la gran mayoría de los mercados a partir de 1974, y junto con una estrategia de apertura comercial y financiera han sido consistentes con las necesidades de inversiones orientadas hacia mercados de exportación» (Zabala, 1987). No obstante que la apertura económica de los años setenta incidió positivamente en la atracción de capitales extranjeros, la situación político-social continuaba siendo un obstáculo para la llegada de IED. El retorno a la democracia en los años noventa marcó un nuevo punto de inflexión en los flujos de capitales extranjeros, que llegaron a su máximo en 1999, durante el proceso de privatización de compañías de servicios básicos (agua, luz y gas). (Ver gráfico 1).

Al examinar la materialización de la IED en Chile, puede observarse que esta corresponde principalmente a la explotación de recursos naturales, en que la minería representa más de un 30\% del total materializado en los últimos 30 años y a la adquisición de empresas de servicios, con cerca de un $30 \%$ del total, tras el proceso de privatización efectuado durante los años noventa,

Gráfico i. Inversión Extranjera Directa en Chile, i974 - 2007.

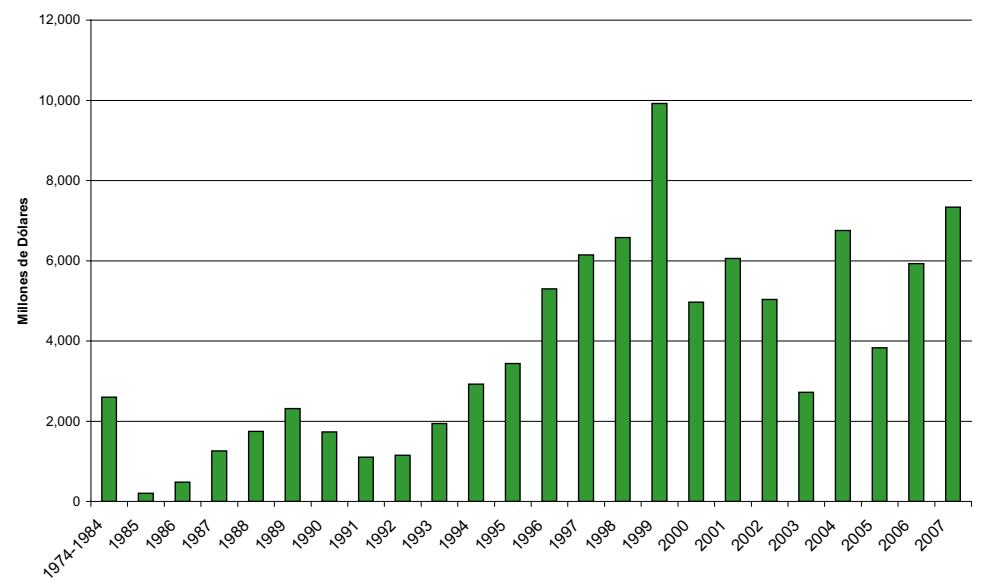

Fuente: Elaboración de los autores a partir de datos del Cinver 
principalmente de empresas eléctricas, sanitarias y de comunicaciones. A su vez, el origen de los capitales invertidos en Chile coincide con las tendencias internacionales y proviene principalmente de países desarrollados. Al respecto, América del Norte (excluido México) y Europa concentran alrededor de un $84 \%$ del total de la IED en Chile. Por su parte, las inversiones provenientes de América Latina no superan el 10\%.

A pesar del crecimiento de las corrientes de capitales extranjeros hacia Chile durante los últimos años, las inversiones brasileñas no han mostrado el mismo dinamismo y representan solo un $0.50 \%$ del total. Puede observarse un ligero crecimiento de la IBD a partir de 1990, pero no hay indicaciones de que vaya a aumentar sostenidamente en el futuro próximo. Es posible que exista una omisión de tipo contable o estadístico que subvalúe la inversión brasileña debido a la diferencia en los métodos de compilación de datos del Banco Central y del Cinver, así como de la actualización de las bases de datos. Por otra parte, parte importante de los capitales de origen brasileño se invierte a través de terceros Estados (Islas Caimán, Bahamas, etc.), por lo que subvaloran el monto real de la inversión brasileña materializada. Finalmente, existen procedimientos de inversión que no son informados en el país, como son la transferencia de los activos del Bank of America al Banco Itaú, que se examina más adelante. Aun así, la relevancia de la IBD en el total no alcanzaría para revertir el análisis del caso.

La escasa afluencia de capitales brasileños al país obedece a diversas razones. En primer lugar, los países latinoamericanos han sido clasificados como inversionistas "tardíos» a raíz de la crisis de la deuda de los años ochenta y el costo de recuperación que esta significó para ellos. Según Krug y

TABla i: Distribución geOgráficA DE LA IBD EN ECONOMÍAS SELECCIONADAS (PORCENTAJE)

\begin{tabular}{|l|r|r|r|r|}
\hline & \multicolumn{1}{|c|}{2001} & \multicolumn{1}{c|}{2002} & \multicolumn{1}{c|}{2003} & \multicolumn{1}{c|}{2004} \\
\hline Argentina & 3.81 & 3.46 & 3.45 & 3.18 \\
\hline Bahamas & 13.98 & 16.03 & 14.66 & 14.48 \\
\hline Bolivia & 0.08 & 0.12 & 0.11 & 0.08 \\
\hline Islas Caimán & 34.71 & 37.94 & 33.72 & 25.78 \\
\hline Chile & 0.37 & 0.38 & 0.45 & 0.34 \\
\hline Colombia & 0.30 & 0.05 & 0.09 & 0.07 \\
\hline Ecuador & 0.16 & 0.22 & 0.10 & 0.18 \\
\hline España & 3.89 & 6.80 & 6.19 & 5.43 \\
\hline Estados Unidos & 3.28 & 4.26 & 4.69 & 4.72 \\
\hline Perú & 0.09 & 0.10 & 0.11 & 0.49 \\
\hline
\end{tabular}

Fuente: Tavares (2006) 
Dorotea López y Felipe MuÑoz • La inversión extranjera directa...

Daniels, la crisis de la deuda tuvo un doble impacto en la exportación de capitales. Por una parte, los gobiernos de la región impusieron restricciones a la salida de capitales con el fin de resguardarse de la escasez de divisas. Por otra parte, $y$ a causa del endeudamiento de los países de la región, los bancos estadounidenses redujeron los créditos a esta y con ello las oportunidades de expansión de las empresas latinoamericanas (Daniels, Krug y Trevino, 2007). Esta entrada tardía habría afectado la posibilidad de exportar capitales debido a la «saturación» de los mercados locales en áreas tradicionales, en el caso chileno la minería.

En segundo lugar, las empresas brasileñas realizan muchas de sus operaciones a través de paraísos fiscales, con lo cual se pierde la posibilidad de determinar el origen de la inversión (Tabla 1). De esta forma, muchos de los proyectos realizados con capitales provenientes de Brasil son contabilizados por las economías receptoras como originadas en terceros Estados, subvalorando el real flujo de IBD.

Finalmente, es importante estudiar la evolución de las estrategias de las empresas y el comportamiento de los capitales brasileños. Al analizar la IBD se acostumbra distinguir tres etapas: antes de 1982, 1982 - 1993 y a partir de 1993. Mientras la primera se caracteriza por la expansión ligada a la actividad petrolífera y de servicios financieros, la segunda, que coincide con la década perdida latinoamericana, se caracteriza por una disminución de los flujos de IBD, los cuales se recuperarían en la tercera etapa, a partir de las reformas de comienzos de los años noventa y de la estabilización monetaria de 1994. Al revisar la distribución geográfica de los proyectos ejecutados por capitales brasileños en las diferentes etapas, puede observarse que Chile no se encuentra entre los principales destinos (Tavares, 2006).

Diversos motivos explican el escaso interés de las empresas brasileñas por invertir en Chile a lo largo de estos años. En primer lugar, el tamaño del mercado chileno no es un atractivo para los inversionistas extranjeros y en segundo lugar, las ventajas comparativas chilenas (recursos naturales, ubicación geográfica) a menudo no resultaron atractivas para las grandes compañías brasileras. Al analizar los planes de internacionalización de las principales empresas brasileñas podemos ver que Chile no ofrecía las condiciones requeridas para la materialización de la inversión.

La principal empresa transnacional brasileña, Petróleo Brasileiro S.A. (Petrobras) $^{3}$, ha desarrollado una estrategia de internacionalización basada en la integración vertical de sus

De acuerdo con el Informe sobre las Inversiones en el Mundo 2007, de la UNCTAD (World Investment Report 2007: Transnational Corporations, Extractive Industries and Development), Petrobras se ubicó como la decimotercera empresa transnacional proveniente de países en desarrollo, con inversiones por 8.290 millones de dólares. 
actividades. De esta forma, los proyectos privilegiados por la compañía se relacionaron con: 1) la exploración y producción de petróleo; 2) la refinación, transporte y comercialización de petróleo; 3) la distribución de gas a través de estaciones de servicios; y 4) la distribución de gas natural ( $\mathrm{Da}$ niels, Krug y Trevino, 2007). Frente a las prioridades de expansión que la empresa había definido, Chile reunía los requisitos necesarios para que la compañía decidiera invertir en el país. En primer lugar, el país no cuenta con yacimientos petrolíferos ni reservas de gas, y segundo, el mercado es demasiado pequeño para que la distribución y comercialización de estos productos resulte atractiva, en especial, si se considera que ellas ya están controladas por cuatro grandes actores (COPEC, Shell, Esso y Terpel).

La segunda compañía que ha desarrollado una amplia estrategia de expansión fuera de Brasil en los últimos años ha sido la minera Companhia Vale do Rio Doce (CVRD). Dedicada principalmente a la producción de hierro, esta empresa desarrolló una estrategia de internacionalización buscando dos objetivos: «diversificarse lejos de Brasil y el hierro» (UNCTAD, 2007). Por estos motivos, las inversiones de la empresa se centraron en Europa y Norteamérica. Una vez consolidado su plan de expansión, la CVRD ha comenzado los estudios para desarrollar proyectos mineros en Chile.

Del análisis del comportamiento de las grandes empresas brasileñas pode- mos extrapolar dos grandes razones que explicarían el aparente desinterés de los inversionistas brasileños en Chile: un mercado insuficiente y la ausencia de recursos naturales estratégicos para sus planes de expansión.

A pesar de la baja proporción que corresponde a la IBD en el total de la inversión en Chile, existe un creciente número de inversiones importantes en diversos sectores económicos nacionales, tales como el industrial y el financiero.

La primera gran empresa brasileña que se instaló en Chile fue Metalúrgica Gerdau S.A., que en 1992, al ver una oportunidad en el mercado del acero, decidió invertir en Chile con el fin de abastecer la creciente demanda local. El ingreso de Gerdau se materializó mediante la compra de compañías existentes en Chile y, luego de comprobar las crecientes oportunidades del mercado, mediante la construcción de una planta en 1997. Las siguientes ampliaciones del Grupo se realizaron a través de la capitalización de las utilidades generadas en el país mediante la compra de terceras empresas que le permitieran aprovechar las economías de escala y sinergias de un proceso de integración vertical y horizontal de su producción. En la actualidad, el Grupo Gerdau da empleo a cerca de 1000 personas en las distintas compañías que controla en Chile.

El ingreso del Banco Itaú al mercado financiero chileno en 2006 no responde a una inversión tradicional, puesto que la operación que permitió su entrada no sig- 
Dorotea López y Felipe MuÑoz • La inversión extranjera directa...

\section{GrÁfico 2. IBD EN CHILE POR SECTORES ECONÓMICOS}

$$
\text { I974- } 2007
$$

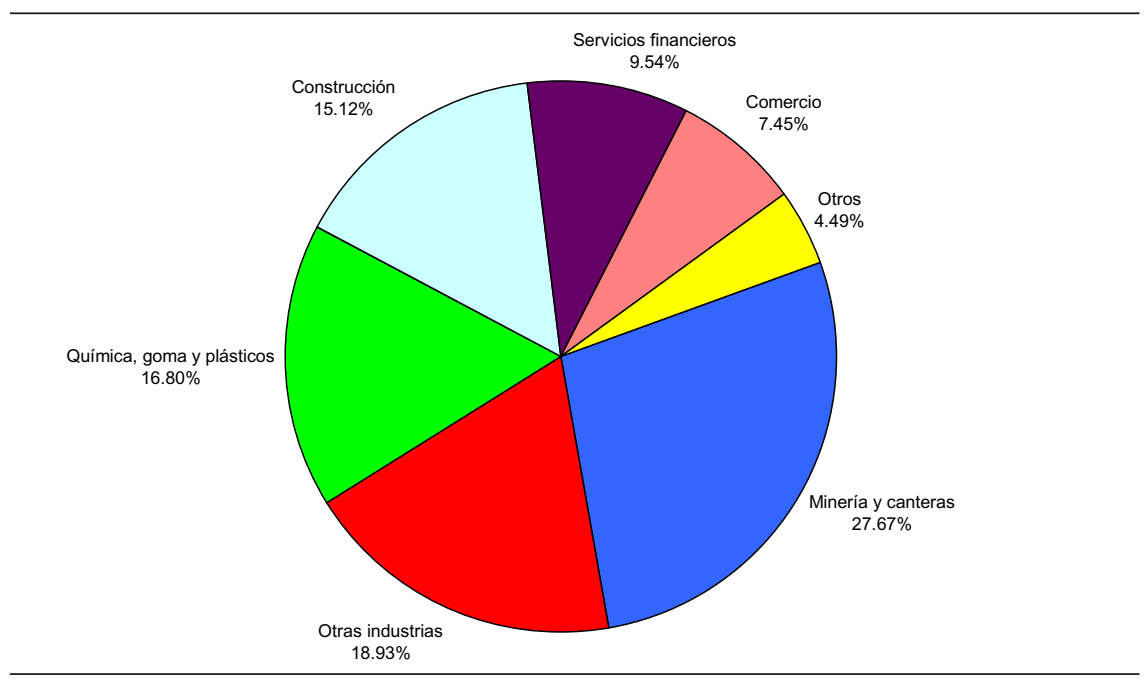

Fuente: Elaboración de los autores a partir de datos del Cinver

nificó un ingreso real de capitales al país. Para materializar su plan de expansión en América Latina, el Banco Itaú acordó con el Bank of America el traspaso del control de las operaciones de este a través de BankBoston, en Brasil, Chile y Uruguay. De esta forma, Itaú controlaría las operaciones en estos países, a cambio de lo cual entregaría al Bank of America un porcentaje de acciones. Para efectos de la transacción, los activos que poseía el BankBoston en Chile fueron valorados en 550 millones de dólares.

El mecanismo de ingreso a Chile de las medianas empresas de capitales brasileños suele repetir un mismo patrón de comportamiento. Hemos podido detectar un importante número de empresas que han ingresado al país a través de la compra de distribuidores locales que comercializaban sus productos. Esta estrategia les ha permitido expandir la oferta y variedad de productos en el mercado local, así como aumentar su participación en los diferentes mercados locales y sus utilidades.

Es interesante notar que la distribución de la IBD no sigue el mismo patrón que la inversión total materializada en Chile. Mientras que a nivel agregado la minería y los servicios básicos acaparan alrededor de un $50 \%$ del total, en el caso de Brasil la inversión se distribuye de manera equitativa entre sectores económicos importantes para el país. El sector industrial concentra alrededor de un $35 \%$, los servicios un $32 \%$ y la minería un $27 \%$ (gráfico 2).

Finalmente, y respondiendo a la centralización que existe en Chile, las 
inversiones brasileñas se han instalado principalmente en Santiago o sus alrededores. De esta forma, podemos apreciar que el $51 \%$ de la IBD se ha materializado en la Región Metropolitana. Junto a lo anterior, cerca del $35 \%$ de esta inversión se ha destinado a proyectos multirregionales, que suelen tener a Santiago como centro de operaciones. La segunda región en importancia para la inversión brasileña es la VIII Región, del Bío Bío, que concentra solo el $8.32 \%$ del total. Es importante destacar que de acuerdo con las estadísticas del Comité de Inversiones Extranjeras, seis regiones del país no habrían recibido capitales brasileños.

\section{iII. Percepciones acerca de LAS INVERSIONES BRASILEÑAS EN Chile}

La estrategia chilena de orientación hacia el sector externo ha logrado amplio consenso entre los distintos actores involucrados, tanto partidos políticos como empresarios, gobierno y sociedad civil. La definición de la inversión como eje fundamental del desarrollo y la temprana apertura de los mercados a la competencia externa son elementos fundamentales en este consenso. En esta línea, el principio de no discriminación parece haber permeado a todos los sectores chilenos.

El proceso de trasnacionalización de los capitales extranjeros es relativamente nuevo para los países latinoamericanos. La inversión entre ellos ha fluido como parte de su estrategia y de su cercanía geográfica, más que como resultado de una política de atracción. En el marco de la estrategia chilena de atraer IED, la región no ocupaba un lugar preponderante. Actualmente, Brasil se ha convertido en un actor estratégico dentro de la región en el proceso de asignación de recursos orientados a promover Chile como destino atractivo para el capital extranjero.

Por lo anterior, los distintos grupos entrevistados coincidieron en cuanto a las ventajas de la inversión, incluyendo la brasileña, para el país. Como consecuencia de ello, las observaciones sobre la IED en Chile son de carácter general, y no hacen especial hincapié en los capitales brasileños. En esta sección se presentan los resultados de la investigación sobre las percepciones del gobierno, la sociedad civil y las asociaciones gremiales o empresarios locales sobre los flujos brasileños a Chile.

\section{Percepción del Gobierno}

El carácter transversal de la inversión da lugar a que las instituciones encargadas directamente de esta sean numerosas y difíciles de coordinar. En Chile, se relacionan con el proceso de inversión principalmente la Corfo, el Cinver, la Direcon y la Gerencia de Inversiones del Ministerio de Hacienda. Las entrevistas estuvieron dirigidas a los agentes involucrados de manera general en el proceso de inversión.

A pesar del bajo porcentaje que representa la inversión brasileña den- 
Dorotea López y Felipe MuÑoz • La inversión extranjera directa...

tro del total de la inversión extranjera en Chile, ella se ha materializado en sectores relevantes para la economía y el empleo. A juicio de las autoridades, las inversiones procedentes tanto de las pequeñas como de las medianas y grandes empresas son positivas para el desarrollo y cumplen con los requisitos que impone la legislación chilena.

El Gobierno ha manifestado creciente interés en atraer capitales de Brasil, para lo cual la Corfo está diseñando un programa para que las empresas brasileñas inviertan en campos relacionados con productos para la minería en la región de Arica y se están evaluando otros para la ejecución de proyectos más intensivos en tecnología. Asimismo, se considera que atraer capitales brasileños significa utilizar menos recursos, ya que las autoridades perciben que Chile se ha posicionado en materia de ventajas ligadas a su estabilidad, transparencia y orden, elementos que son el principal atractivo del país para los inversionistas extranjeros.

Conscientes de que el tamaño del mercado no constituye un atractivo para las empresas de capitales brasileños, las autoridades consideran que es primordial promocionar las ventajas que Chile ha adquirido a través de sus acuerdos comerciales preferenciales con otras economías para poder utilizar al país como plataforma de exportación. «El destino inevitable de las empresas en Brasil es la internacionalización y un socio inmejorable en la región para ese proceso es precisamente Chile» ${ }^{4}$. Según las autoridades, las prioridades de Brasil están dirigidas a México y Argentina. El trato nacional que el Estado chileno otorga a los inversionistas debe seguir siendo un principio de la estrategia chilena.

Existe la creciente impresión de que el D.L. 600 no se estaría adaptando a las nuevas condiciones que enfrentan el país y los inversionistas. El Decreto, que en su momento pudo considerarse un mecanismo atractivo para los inversionistas resulta hoy casi obsoleto. De esta forma, crece la idea de que el sistema de incentivos para atraer capital extranjero a Chile es cada vez más ineficiente. Al respecto, los senadores Jorge Pizarro y José García coinciden en que es preciso revisar el actual Estatuto de Inversión Extranjera contenido en el Decreto Ley 600 y que rige desde 1974.

«Es urgente generar incentivos y hay que revisar el funcionamiento del D.L. 600 , porque las condiciones actuales son muy distintas a las de hace 20 años. Las áreas de pesca, forestal, los servicios y la producción vitivinícola han aumentado y hay que tomar conciencia de que, si queremos crecer, la inversión es clave» ${ }^{5}$.

4 Carlos Furche, Director General, Direcon. Comunicado de Prensa, Chile y Brasil Intensifican Tercera Etapa de Intercambio: Invertir para Nuevos Mercados, 22 de noviembre de 2007.

5 Pizarro, Jorge. <www.senado.cl>, visitado el 10 de abril de 2008. 
Asimismo, en lo que respecta a promover la inversión aún falta coordinación al interior del Gobierno, a lo que hay que sumar que el Comité de Inversión Extranjera podría tener el problema de doble militancia, ya que por un lado es representante del Estado frente al inversionista y por el otro tiene un papel promotor.

El empleo, uno de los objetivos fundamentales en la búsqueda de inversiones, se ha visto beneficiado por los capitales brasileños, toda vez que la política de las empresas parece coincidir en que la fuerza de trabajo debe ser nacional. De acuerdo con la información manejada por el gobierno, la Cámara de Comercio de Santiago y las empresas brasileñas en Chile, se estima que la inversión brasileña ha generado aproximadamente 3,500 empleos directos y un número similar de empleos indirectos.

Hay ciertas coincidencias en el elevado costo de los despidos y en que hay que fiscalizar mejor el otorgamiento de licencias médicas. La tasa de sindicalización en Chile es aún muy baja. Según la Organización Internacional del Trabajo (OIT), hasta comienzos de los años noventa la tasa se elevó de manera sostenida, pero a partir de 1994 ese mismo indicador ha venido a la baja. De acuerdo con la OIT, la actual tasa de sindicalización en Chile es de un $11 \%$ (12,9\% hombres y $7,5 \%$ mujeres.).

Las empresas brasileñas son importantes usuarios de las franquicias que ofrece el gobierno para la capacitación de recursos humanos y realizan un gasto importante en este rubro, en par- ticular cuando hacen uso intensivo de tecnologías desarrolladas en Brasil.

Hasta el momento a las autoridades no parece preocuparles el impacto ambiental de las inversiones brasileñas. Posiblemente esto obedezca a que no se releva información sobre empresas que tengan plantas con producción importante, salvo el caso de Gerdau Aza, cuyo funcionamiento no ha presentado problemas ambientales. Sin embargo, las autoridades consideran que eventualmente los trámites medioambientales pueden generar retrasos en la inversión ya que aún existen problemas de carácter burocrático.

Finalmente, las autoridades coinciden en que debido a que Chile depende de la energía que otros países le venden, el tema energético puede eventualmente representar una limitante para la atracción de capital extranjero. Asimismo, existe preocupación por los temas pendientes para reducir los tiempos de espera de los procesos burocráticos y la necesidad de seguir invirtiendo en mejoras de la infraestructura y las comunicaciones.

\section{Percepciones de la sociedad civil}

Hay consenso en que la política de apertura no ha dado lugar a discriminación contra los inversionistas brasileños. Por el contrario, la percepción es positiva respecto de su participación en los ámbitos culturales y económicos. Para estos efectos se entrevistaron, principalmente, a académicos y sindicatos. 
Dorotea López y Felipe MuÑoz • La inversión extranjera directa...

La impresión general es que el país ofrece un marco de certeza y estabilidad que lo hacen muy atractivo. Asimismo, hay conciencia en que dada la cercanía y el tamaño del mercado no se justifica instalar fábricas en Chile. Por esta razón, se considera que el país podría aplicar una política de inversión que favoreciera a las empresas brasileñas.

\section{Las organizaciones sindicales}

En Chile, la tasa de sindicalización es baja, y las empresas brasileñas que operan en el país no son ajenas a esta realidad. Por este motivo, solo se realizaron entrevistas a organizaciones sindicales relacionadas con el sector financiero.

Las pequeñas y medianas empresas que tienen menos de 18 empleados, que es el caso de varias empresas brasileñas instaladas en Chile, no siempre tienen sindicatos. En el último año, el movimiento sindical en los distintos sectores ha tomado fuerza y manifestado su descontento con algunas políticas de las empresas. Sin embargo, han resaltado que no consideran que sea una práctica de las empresas brasileñas sino de una especie de adecuación a la realidad chilena. Desde su punto de vista, las empresas que operan en Chile y han tenido alta rentabilidad no han incrementado de forma significativa las remuneraciones y en muchos casos no han mejorado las regulaciones sobre la jornada laboral.

En el campo financiero, existe una Coordinadora de América del Sur entre
Brasil, que es sede principal, Argentina, Uruguay y Chile, cuyo objetivo es el intercambio permanente de los problemas sindicales locales, posiciones y soluciones a nivel internacional (Órgano Oficial del Sindicato Nacional de Trabajadores de Empresa Banco Itaú, 2007).

En lo referente a la consulta sobre los beneficios en materia de capacitación obtenidas por las empresas mediante la utilización de la franquicia tributaria para capacitación (SENCE), los empleados del sector financiero tienen la impresión de que ella se utiliza únicamente por las ventajas tributarias que acarrea para la empresa, en desmedro de la calidad de la capacitación ofrecida, ya que siempre estaría dirigida al mismo Instituto, que esta ligado al sector financiero.

\section{Académicos y organizaciones internacionales}

Existe la percepción de que la inversión brasileña es muy baja y que ella debería incrementarse como consecuencia de la mayor integración regional. Se dice que existe poca complementariedad con Chile en cuanto a los fines que persigue Brasil en su proceso de internacionalización. Dadas la cercanía geográfica y el tamaño del mercado no se justifica instalarse en Chile, ya que el mercado puede ser explotado mediante exportaciones. Además, en su opinión, las empresas brasileñas buscarían ampliar sus mercados o explotar recursos naturales que diversifiquen su produc- 
ción en Brasil, características que no encontrarían en Chile.

Chile debe plantearse como objetivo atraer mayor inversión y aprovechar las ventajas que le otorgan los acuerdos preferenciales, ya que para Brasil el país sería el canal natural de acceso al Asia. En consecuencia, debería aplicar una política de atracción más agresiva que no se sustente únicamente en instrumentos no discriminatorios. La conectividad física es aún precaria y debe ser reforzada para poder ser atractivo como plataforma de exportación.

Para fortalecer su atractivo para los inversionistas, Chile debe plantearse cuatro objetivos: mejorar la infraestructura física, invertir en capacitar su capital humano, reforzar los derechos de propiedad intelectual y mejorar la distribución del ingreso.

Entre los desafíos que enfrenta Chile, el Banco Mundial identifica el tiempo y costo que se requieren para resolver los casos de quiebra, incluidos los costos legales y al monto de los honorarios de los sindicos, abogados y contadores. La tasa de recuperación mide la eficiencia de ejecución de una hipoteca o procedimiento de quiebra, expresada en términos de cuántos centavos por dólar recuperan los demandantes de la empresa que cayó en insolvencia. En Chile, este es de 20,0 en comparación con el promedio regional de 25,7 y un promedio de la OCDE de 74,0.

A pesar de la percepción de que la legislación es rígida y anticuada, el Índice de Rigidez del Empleo, del Banco
Mundial $^{6}$, que mide la dificultad para contratar un trabajador nuevo, cuan restrictivas son las regulaciones sobre el horario de trabajo y las dificultades para el despido, califica a Chile con un valor de 24 , comparado con un promedio regional de 31.7 y para los países de la OCDE de 33,3. Esto relativiza la percepción de inflexibilidad de la legislación laboral chilena, que se ha tornado más rígida en los últimos años, pero continúa siendo más flexible que la de los demás países.

Los académicos consideran que el D.L. 600 debe modernizase, ya que no estaría entregando ventajas reales a los inversionistas.

A juicio de los académicos, Chile debe incentivar inversiones intensivas en tecnología, que tradicionalmente se han buscado en Europa y Estados Unidos. En su opinión, Brasil puede ser una importante fuente de inversiones de alta tecnología.

\section{Percepción de las asociaciones empresariales y de los empresarios locales}

Los agentes involucrados en la inversión chilena, en particular el sector privado, señalan que es necesario generar una política de atracción de inversiones que sea más agresiva y comprometida. Chile no puede seguir descansando en su estabilidad, su transparencia y su

$6 \quad$ El índice da un valor de 0 a 100 , siendo los valores más altos para mercados laborales más rígidos. 
apertura comercial, y debe diseñar una estrategia que para algunos debe ser discriminatoria en cuanto al destino de la inversión e involucrar aspectos tributarios o normativos más profundos. Por ejemplo, debería promover inversión y desarrollo en el extranjero optando por una estrategia que le permita convertirse en plataforma exportadora de servicios que no sean intensivos en recursos humanos.

La apertura de la economía a través de sus diversos tratados de libre comercio, la certeza jurídica y la estabilidad política del país han dejado de ser atractivo suficiente para los inversionistas.

«...las alternativas de inversión en países vecinos como Argentina o Perú, que está dando una serie de facilidades hoy día para poder instalarse y aumentar la inversión, indudablemente que se convierten en mercados más atractivos para los inversionistas, donde la legislación permite de una u otra manera trabajar mejor» (Valencia, 2007).

Si bien han existido campañas que tratan de resaltar las ventajas comparativas del país, destacando aquellos sectores económicos en que puede darse valor agregado a la inversión, es preciso evolucionar de la estrategia de clusters aislados, como el minero, hacia un modelo país más definido. En opinión de los gremios y del sector privado, los destinos para las inversiones son cada vez más competitivos y el buen ambiente de negocios que Chile pueda ofrecer ya no es atractivo suficiente para los capitales extranjeros. Es necesario que Chile implemente una política más agresiva de atracción, apostando por inversiones en sectores considerados clave para el desarrollo.

El gobierno ha aplicado una estrategia de atracción de carácter transversal. Existen programas como el denominado Plataforma de Inversiones, que son conceptualmente adecuados pero no han funcionado y aún son muy abstractos. En opinión del sector privado, en la práctica en Chile no existe un modelo concreto, como ocurre con los centros de llamado en la India o con los paraísos tributarios, en los que el inversionista tiene claro que va a encontrar lo que busca, lo que hace que en estos casos el objetivo de atracción del modelo funcione y además disminuye la importancia de otros factores que podrían resultarle negativos. El diseño para Chile puede pasar por el tema regulatorio o impositivo y debe acompañarse de una estrategia a largo plazo que defina el tipo de inversiones que al país le interesa. Algo ha faltado y es preciso tener claro que Chile no es el único país en el proceso de búsqueda de capitales y no parece haber logrado generar una apuesta clara y concreta en esta materia.

Para el caso de las inversiones brasileñas, los agentes han identificado algunos sectores que podrían ser atractivos y que en Chile tendrían un evidente efecto positivo para la economía. Se han señalado las siguientes estrategias interesantes:

- Proyectos de alta tecnología, que al no ser intensivos en mano de obra puedan realizarse en el país. 
- Inversiones en biotecnología: Brasil tiene nichos de innovación muy importantes, pero no parecen estar mirando hacia Chile y es necesario implementar políticas que lo hagan atractivo.

- Proyectos relacionados con productos para la minería.

Existe un acercamiento entre la Sociedad de Fomento Fabril (Sofofa) y la Federación de Industrias de Sao Paulo (FIESP), que firmaron en julio pasado un memorando de entendimiento. Según la primera, Chile y Brasil enfrentan una tercera etapa en sus relaciones bilaterales, que apunta a fomentar la inversión brasileña en el país para mirar hacia nuevos mercados. Este año, tuvo lugar el Segundo Encuentro Empresarial ChileBrasil, que fue dirigido por el presidente de la Sociedad de Fomento Fabril, Bruno Philippi. La próxima fase es la integración productiva para terceros mercados. Dicho memorando incentiva acciones de promoción comercial entre ambos países y fomenta la identificación de los sectores más dinámicos para estimular asociaciones y acuerdos comerciales.

Un importante grupo económico percibe que la legislación laboral es cada vez más proteccionista y no ha tenido avances en el sentido de introducir normas que se ajusten a una realidad mundial crecientemente flexible y que enfrenten los problemas estructurales del mercado laboral chileno ${ }^{7}$. Hay

7 El Mercurio, Editorial, ¿Nuevo Código del Trabajo?, 28 de febrero de 2008. coincidencia en que esto aumenta la tasa de desempleo entre las mujeres, los jóvenes y los trabajadores menos calificados. Chile debe apostar a capacitar su capital humano para poder atraer inversión en proyectos más intensivos en tecnología y capital.

\section{PeRcepción de los}

INVERSIONISTAS BRASILEÑOS SOBRE LA EXPERIENCIA EN CHILE

Las inversiones brasileñas en Chile se han materializado a través de empresas de diferentes tamaños en diversos sectores de la economía. En la presente sección se recopilan las percepciones de los empresarios brasileños sobre diversos aspectos relacionados con la inversión en Chile, tales como el escenario del país, los mecanismos de inversión, el mercado laboral y la legislación chilena.

A pesar de las diferencias tanto en lo que respecta a montos de inversión como a los rubros en que ella se ha materializado, los empresarios coinciden en cuanto al marco de certeza política, económica, jurídica e institucional que ofrece el país. A juicio de los entrevistados, Chile ha logrado posicionarse como un país que tiene un sistema democrático maduro y un responsable manejo económico por parte de las autoridades, lo que junto con el respeto de la legislación y los contratos y la solidez del país permiten crear las condiciones que los inversionistas internacionales persiguen para tomar 
Dorotea López y Felipe MuÑoz • La inversión extranjera directa...

la decisión de establecerse en el país. A pesar de esto, sostienen que la burocracia chilena puede llegar a desalentar la inversión, ya que si bien los trámites y procedimientos que deben realizarse son transparentes y de público conocimiento, los tiempos necesarios para obtener respuestas frente a solicitudes y resoluciones por parte de la autoridad son excesivos.

En lo que respecta al trato recibido por los capitales e inversionistas extranjeros, existe consenso entre los entrevistados respecto del trato nacional que otorgan las autoridades chilenas. El principio de no discriminación es plenamente respetado tanto en la legislación como en los servicios públicos. Ninguna de las empresas entrevistadas ha experimentado dificultades o discriminación a causa de la nacionalidad de sus capitales o de la persona de los gerentes.

Al momento de analizar los obstáculos que enfrenta la IBD en Chile, el principal factor que destacan grandes y medianos empresarios es el tamaño del mercado. Chile no representa un mercado atractivo para los inversionistas extranjeros que, pese a reconocer el alto poder adquisitivo de los potenciales consumidores en comparación con el resto de América Latina, consideran que su número no justifica establecerse o ampliar sus instalaciones en el país. Por este motivo, gran parte de las empresas brasileñas que operan en Chile solo se dedican a la distribución de bienes producidos en Brasil y no optan por producir en el país. En el caso de los pequeños empresarios, estos se orientan a satisfacer demandas locales acotadas, por lo que el tamaño del mercado nacional no influye en sus decisiones de inversión.

En los últimos años, Chile ha desarrollado una activa política de inserción en la economía internacional basada en la suscripción de acuerdos comerciales preferenciales. Esta política permite que los bienes producidos en Chile ingresen con ventajas a más de un $50 \%$ del mercado mundial. A pesar de esta política, las empresas instaladas no perciben a Chile como una potencial plataforma para operaciones fuera del mercado local. A juicio de los entrevistados, esta estrategia, destinada a crear una plataforma de exportación, no ha sido lo suficientemente atractiva ni proporciona las condiciones e incentivos necesarios para expandir sus planes de operaciones en Chile. Las empresas brasileñas que proyectan al exterior las operaciones que realizan en Chile solo abastecen mercados andinos, muchos de los cuales son herencia de las empresas que adquirieron al momento de ingresar a Chile y no forman parte de planes de expansión propios.

Los empresarios brasileños señalan que los mecanismos existentes en Chile para el ingreso al país son eficientes y no presentan obstáculos para materializar la inversión. La gran mayoría de las inversiones materializadas en el país se han realizado a través del Capítulo $\mathrm{XIV}^{8}$, ya que los montos involucrados

\footnotetext{
8 Capítulo XIV del Compendio de Normas y Cambios Internacionales: Mecanismo por el cual ingresan a Chile capitales extranjeros.
} 
no permitirían aplicar las disposiciones del DL 600. Por otra parte, los empresarios destacan que actualmente el DL 600 no representa ninguna ventaja frente al Capítulo XIV, ya que la única que podría percibirse como tal, el acceso al mercado cambiario formal, existe sin necesidad de utilizar el Decreto. A su vez, quienes han ingresado al país utilizando el DL 600 han renunciado a la invariabilidad tributaria, argumentando que la tasa impositiva aplicada actualmente en Chile, inferior a la ofrecida por el Decreto, y la estabilidad político-económica del país son garantía suficiente para su inversión.

Para los empresarios brasileños, la ausencia de programas de incentivo a la inversión es un problema para atraer inversiones. Según parte de los entrevistados, el gobierno debe otorgar incentivos tributarios para que se realicen inversiones nuevas o se amplíen empresas ya instaladas. Sin estos incentivos difícilmente podrían atraerse más capitales brasileños hacia el país, ya que los demás incentivos (escenario país, trato nacional, etc.) no serían suficientes.

En cuanto a la defensa de la competencia, los entrevistados no consideran que la legislación nacional les sea desfavorable. Reconocen que, en general, el mercado chileno es bastante competitivo. A pesar de esto, identifican en ciertos sectores de la economía una fuerte concentración en torno a pocos actores que operarían de manera oligopólica, lo que afectaría directamente sus operaciones en el país. Entre estos grupos señalan al retail chileno y a los productores de azúcar. En lo que se refiere al primero, los empresarios brasileños consideran que el hecho de que existan pocas empresas los afectaría, pues estarían ejerciendo su poder de mercado para conseguir mejores precios en los productos que adquieren. A su vez, para poder ingresar al mercado local, el poder de mercado de algunas empresas distribuidoras y grandes tiendas sería una barrera a la entrada de nuevos productos. En el segundo caso, la falta de competencia en el mercado del azúcar y el hecho de que es un insumo muy importante para determinadas industrias, desalentarían la instalación de empresas que lo requieran.

La legislación medioambiental chilena, en línea con el creciente interés mundial por la conservación y respeto de la naturaleza, ha vivido un continuo proceso de transformación en los últimos años, a la vez que las autoridades se han tornado más exigentes para la aprobación de proyectos que involucren un posible impacto ambiental. Para los empresarios brasileños cuyas operaciones en el país tienen impacto ambiental, este escenario no representa un problema y respetan el derecho del Estado de Chile de proteger su entorno. Junto con esto, destacan que los servicios públicos encargados de fiscalizar el cumplimiento de la normativa suelen entregar a las empresas las flexibilidades necesarias para que estas puedan cumplir con las disposiciones, sin que esto constituya un costo inalcanzable. De todos modos, reconocen que, en el 
Dorotea López y Felipe MuÑoz • La inversión extranjera directa...

futuro, un celo excesivo en la aplicación de la normativa o cambios en la misma pueden traducirse en un problema para la operación e instalación en el país, por lo cual la legislación medioambiental podría potencialmente transformarse en un desincentivo para los inversionistas extranjeros.

Para los empresarios brasileños, en Chile la regulación de precios no es un tema que represente un problema. Reconocen que la mayoría de los precios no están afectos a intervención por el gobierno, pudiendo las empresas actuar libremente en el mercado. Solo el sector financiero sostiene que la fijación de techos máximos a la tasa de interés impide el desarrollo global de la banca, por lo cual hay sectores de la población que no pueden acceder a los servicios de esta.

Los empresarios brasileños consideran que la infraestructura chilena es adecuada para la realidad del país, pero manifiestan su preocupación por el excesivo centralismo chileno, en que todo se concentra alrededor de Santiago. Las regiones chilenas no estarían ofreciendo las condiciones mínimas para invertir (proveedores, cadenas productivas, servicios públicos), por lo cual consideran que las autoridades debieran velar por que en estas zonas se generen dichas condiciones, ya que sus inversiones podrían localizarse en otras provincias.

Para los empresarios brasileños, un sector que hoy influiría negativamente en las decisiones sobre instalación y/o expansión de operaciones en Chile es el sector laboral. Los últimos cambios producidos en el mercado laboral, la legislación laboral y el movimiento sindical chileno restarían atractivos a Chile como destino de inversiones. Si bien estos problemas no afectan de igual manera a las distintas empresas, detectándose diferencias según el tamaño de cada una de ellas, independiente del tipo de empresa, todos los entrevistados perciben las materias laborales como un obstáculo a la inversión.

Al analizar el mercado laboral chileno, los entrevistados sugieren que los costos de la mano de obra en Chile son muy elevados en comparación con personal de similares características en otros países. La evidencia parece apuntar a que el mercado laboral chileno, además de presentar algunos problemas estructurales que se mantienen en el tiempo, ha experimentado una serie de cambios como resultado de la dinámica de los tiempos, para los cuales la actual legislación no entrega respuestas satisfactorias. Si bien reconocen que los trabajadores chilenos son altamente calificados, ello no justificaría pagar los sueldos que el mercado estaría exigiendo.

La legislación laboral es percibida como una legislación anticuada, que no ha logrado adaptarse a las nuevas condiciones que imponen los mercados. Para las grandes empresas, el cumplimiento de la legislación no resulta inconveniente, pero las empresas medianas y pequeñas señalan que las reglas y controles a cargo de inspectores de la Inspección del Trabajo, dependiente del Ministerio del Trabajo, constituyen una 
carga muy alta para su administración. Junto a lo anterior, hay coincidencia en que la justicia laboral tiene un sesgo a favor del empleado, en particular la Inspección del Trabajo. De esta forma, existe la idea de que cualquier proceso que enfrente a la empresa con un empleado será fallado en favor del último, sean cuales fueren los argumentos invocados.

Un tercer aspecto mencionado por los entrevistados en materia laboral se relaciona con el movimiento sindical y el funcionamiento de los sindicatos en Chile. El tema sindical atañe solo a las grandes empresas, ya que las medianas y pequeñas suelen no tener sindicatos. En opinión de los empresarios entrevistados, el movimiento sindical chileno está viviendo un creciente grado de politización, con lo cual la lucha sindical no estaría aportando al proceso de construcción de confianzas empleador-empleado y no solo jugaría contra los intereses de las empresas sino también de los propios trabajadores. A su vez, destacan que la irrupción de un movimiento sindical más violento en sectores estratégicos de la economía (minería, acuicultura y frutícola) es un desincentivo a la llegada de nuevas inversiones ante la posibilidad de que los conflictos se repitan en otras industrias o exista una escalada de violencia que pudiera afectar sus inversiones. De todos modos, se reconoce que los sindicatos actúan, y pueden actuar, como interlocutores entre los intereses de los trabajadores y las empresas y que una sana relación entre estos favorece a los intereses de ambos, que no son necesariamente antagónicos.

A pesar de que encontramos que las materias laborales son algunos de los principales problemas y preocupaciones de los inversionistas brasileños, estos destacan como muy positivos los incentivos que el Estado otorga a las empresas para la capacitación de sus trabajadores. El programa del Servicio Nacional de Capacitación (SENCE), a través del cual las empresas pueden descontar de sus impuestos el gasto efectuado en capacitación, es considerado un excelente incentivo para estos fines. Todas las empresas utilizan la franquicia tributaria, destacando lo transparente, eficiente y fácil que es su utilización.

Finalmente, al ser consultados sobre la protección de la propiedad intelectual, la legislación impositiva y las normas técnicas aplicadas en Chile, los empresarios brasileños coincidieron en señalar que ellas se ajustarían perfectamente a la realidad nacional y que su aplicación no generaría obstáculos o desincentivos a la inversión. Los procedimientos relacionados son claros y expeditos, y destacan el trato nacional que les otorgan los pertinentes.

\section{v. Conclusiones}

A continuación se ofrecen algunas propuestas para desarrollar una agenda bilateral entre Chile y Brasil con el objeto de incentivar el flujo de capitales entre ambos países. 
Dorotea López y Felipe MuÑoz • La inversión extranjera directa...

\section{Creación de una instancia de co-} ordinación bilateral entre organismos relacionados con inversiones

Uno de los principales obstáculos para mejorar el flujo de capitales entre Brasil y Chile ha sido la falta de comunicación entre ambos países en materia de promoción de inversiones y de identificación de complementariedades que hagan atractivo para los inversionistas desarrollar una relación bilateral. Chile ha demostrado creciente interés en atraer capitales brasileños, pero debido a la falta de canales de información eficientes, estas oportunidades son desconocidas por los potenciales inversionistas brasileños.

La creación de una instancia de coordinación entre los distintos organismos encargados de la promoción de inversiones en Brasil y Chile permitiría centralizar y distribuir de manera eficiente información relevante para los inversionistas. A través de instancias como esta, los gobiernos podrán promocionar políticas y programas de inversión en que los capitales de la contraparte puedan representar un apoyo a la consecución de sus objetivos.

Dentro de los programas que el gobierno de Chile no ha podido promocionar con fuerza en Brasil se encuentra, por ejemplo, el proyecto de Chile País Plataforma. Este programa busca atraer inversiones al país a través de la promoción del acceso preferente que Chile posee a diversos mercados gracias a su red de acuerdos comerciales.

\section{Fortalecimiento de las relaciones} entre los sectores privados

Además de crear una instancia para coordinar la comunicación entre los organismos gubernamentales chilenobrasileños, es importante fortalecer las relaciones entre los sectores privados de ambos países. En este sentido, la Cámara Chileno Brasileña de Comercio juega un papel fundamental al reunir y representar los intereses de empresarios de ambos países y según los empresarios brasileños debería ser más activa en este propósito. A su vez, los gobiernos deberían apoyar las iniciativas del sector privado como por ejemplo aquella desarrollada por Sofoca, por Chile, con FIESP, por Brasil.

\section{Conectividad física y facilitación de comercio}

La conectividad física de la región sudamericana continúa siendo un obstáculo para las relaciones económicas entre Brasil y Chile. En primer lugar, no existen carreteras de calidad que conecten ambos países. Luego, la duplicación de los trámites necesarios para llegar de un país a otro debido a que para ello es preciso pasar por Argentina o Bolivia impone costos a los empresarios que reducen su interés por el intercambio de bienes. Estos problemas de conexión desalientan tanto las relaciones comerciales entre Brasil y Chile como la posibilidad de que inversionistas brasileños piensen en Chile como destino para realizar inversiones destinadas a abastecer el mercado de Brasil. Por esto, es fundamental que ambos países 
promuevan programas que apoyen la conectividad física sudamericana y la facilitación del comercio.

\section{Acuerdo de Promoción y Protec- ción de Inversiones}

La ratificación del Acuerdo de Promoción y Protección de Inversiones (APPI) entre Chile y Brasil sería un estimulo para los inversionistas y promovería el flujo de capitales entre ambos países.

\section{Profundización del ACE 35}

La profundización del Acuerdo de Complementación Económica que Chile y Mercosur mantienen vigente (ACE 35) puede ser un elemento importante para fomentar el intercambio comercial y de inversiones entre ambos países.

\section{Acercamiento del sector académi-} co al gobierno y el sector privado en materia de inversiones

Mediante la realización de estudios en que se detecten las necesidades, barreras y oportunidades de inversión, el sector académico puede convertirse en un puente entre el sector privado y el gobierno.

\section{Bibliografía}

Banco Central de Brasil (www.bcb.gov.br). CEPAL (2005), Balance preliminar de las economía de América Latina y el Caribe, Publicaciones de Naciones Unidas, Santiago de Chile (LC/G.2292-P/E).

CEPAL (2005), La inversión extranjera en América Latina y el Caribe 2004, Publi- caciones de Naciones Unidas, Santiago de Chile (LC/G.2269-P/E).

CEPAL (2006), Foreign investment in Latin America and the Caribbean 2005. Publicaciones de Naciones Unidas, Santiago de Chile (LC/G.2309-P/I).

CEPAL (2007), La inversión extranjera en América Latina y el Caribe 2006. Publicaciones de Naciones Unidas, Santiago de Chile (LC/G.2336-P/E).

Confederación de Sindicatos Bancarios (2007), Trabajadores del Mundo Financiero.

Corporación de Fomento a la Producción (CORFO) (2008), Instrumentos para el apoyo de las inversiones en Chile, InvestChile, en <http://www.corfo.cl>.

Corporación de Fomento a la Producción (CORFO) (2007), Guía de Apoyo a la Inversión, en <http://www.corfo.cl>.

Daniels, J.; J. Krug; L. Trevino, (2007). Foreign direct investment from Latin America and the Caribbean, en: Transnational Corporations, Volumen16, número 1, abril del 2007, pp. 27-54.

Deloitte (2007). Invirtiendo en Chile, en: <http://www.deloitte.com/dtt/ article/0,1002,cid\%253D41302,00.html>.

Durán, Valentina (2008), Fiscalización y cumplimiento de las normas medioambientales siguen siendo el punto débil de Chile, Documento de trabajo, Universidad de Chile.

El Financiero, varios números.

El Mercurio, varios números.

Gligo, Nicolás (2007), Políticas activas para atraer inversión extranjera directa en América Latina y el Caribe, Publicaciones de las Naciones Unidas, Santiago de Chile.

Gouvea, Raul (2007), The transnationalization of Brazil's software industry, en: Transnational Corporations, Volumen16, número 1, abril de 2007. pp. 145 - 164.

Hachette, Dominique (1998), Privatizaciones: Reforma estructural pero inconclusa, en: Larraín, F. y R. Vergara, (eds.) La Transformación Económica de Chile, Centro de Estudios Públicos, Santiago de Chile.

Iglesias, Roberto (2007), Os interesses empresariais brasileiros na América do Sul: 
Dorotea López y Felipe MuÑoz • La inversión extranjera directa...

investimentos diretos no exterior, Brasil, FUNCEX.

La Tercera, varios números.

Mideplan (2006), Encuesta de Caracterización Socioeconómica Nacional (CASEN).

OCDE. (2007). Estudios Económicos de Chile, 2007, en: http://www.oecd.org/ dataoecd/39/58/39673573.pdf

Órgano Oficial del Sindicato Nacional de Trabajadores de Empresa Banco Itaú (2007), El Sindicato Informa, diciembre.

Secretaria de la Organización Mundial del Comercio (2003), Informe sobre las políticas y prácticas comerciales de Chile, en: http://www.wto.org/spanish/tratop_s/ tpr_s/tp224_s.htm

SOBEET (2007), Internacionalização das empresas brasileiras, Brasil. Sociedade Brasileira de Estudos de Empresas Transnacionais e da Globalização Econômica e Fórum de Líderes.
Tavares, Márcia (2006), Investimento brasileiro no exterior: panorama e considerações sobre politicas públicas, Publicaciones de las Naciones Unidas, Santiago de Chile.

UNCTAD (2007), World Investment Report: Transnational Corporations, Extractive Industries and Development. (E.07.11.D.9)

Valencia, Héctor (2007), Gerente General del Instituto de Seguridad del Trabajo (IST). Entrevista en: La Consulta Jurídica. 26/12/2007.

World Bank (2007), Connecting to Compete: Trade Logistics in the Global Economy. en: http://www.inviertaenchile.cl/archivos/ LogisticsPerformanceIndex2007 World Bank.pdf.

Zabala, Ricardo (1987), Inversión extranjera directa en Chile 1954 - 1986, en Revista Estudios Públicos N²8, Primavera 1987. 